\section{Brief Review: Basic Properties and Applications of Carbon Nanotubes}

\author{
Supapan Seraphin \\ Department of Materials Science and Engineering, \\ The University of Arizona, Tucson, Arizona \\ seraphin@email.arizona.edu
}

\section{Introduction}

The first publication on the Buckminsterfullerene carbon molecule $\left(\mathrm{C}_{60}\right)$ was in 1985 by Kroto et al. [1]. Not much else happened right after that since samples of $\mathrm{C}_{60}$ were not available for further study. It was the discovery of Krätschmer and Huffman's group [2] in 1990 that really opened up the field. They found a method to produce $\mathrm{C}_{60}$ in gram quantity. This made it possible for researchers around the world to investigate $\mathrm{C}_{60}$ properties and further advanced the field of nanocarbon research. Establishing the existence of a third crystalline form of carbon is one of the most exciting fundamental discoveries in science to date. Inasmuch as we were at the same university with Huffman, we characterized numerous carbon samples produced in his laboratory. It was certainly an exciting time. Iijima found conditions of the arc-discharge technique that could produce multi-walled nanotubes [3]. We also worked closely with a local industry in Tucson, Materials Electrochemical Research Corporation, on commercial-scale production of carbon nanotubes, various encapsulations of nanotubes, and single-walled nanotubes.

Recently, M. Terrones [4] and V.N. Popov [5] published excellent reviews on the synthesis, growth mechanisms, properties, and applications of carbon nanotubes. Terrones shows that the publications on carbon materials have grown exponentially from dozens in early 1991, to over 1,500 in 2001 [4]. Progress is being made not only on the improvement of the production and characterization techniques for nanotubes but also on their applications. Important mechanical, electrical and thermal properties are reported. This article will summarize the main production methods, fundamental principles of the relationship between structure and properties of nanotubes, and several applications based on the electronic and mechanical properties of nanotubes.

\section{Processing Methods}

Carbon nanotubes (CNTs) can be produced using three main methods: arc-discharge, laser ablation, and catalytic growth. Recent development established that solar energy can also be used as an alternative to produce CNTs. Each method still needs to be improved upon to reduce cost and for large-scale production of defect-free nanotubes for industrial applications.

\section{Arc-discharge}

This technique produces fullerenes in the soot and CNTs in the cathodic deposit (negative rod) of the appartus. The relative amount of fullerenes versus CNTs depends mostly on the gas pressure in the chamber. Transmission electron microscopy (TEM) revealed that each nanotube is comprised of coaxial tubes of graphitic sheets, ranging in

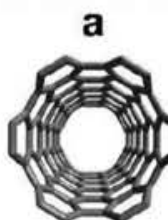

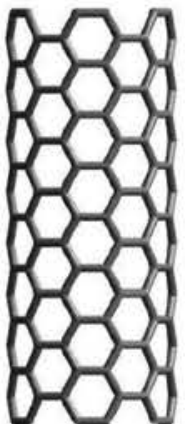

armchair
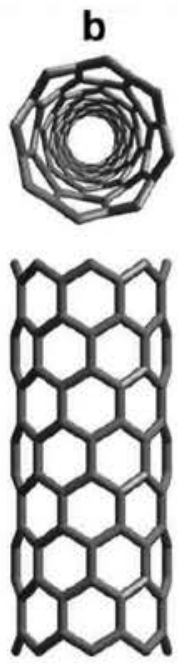

zigzag
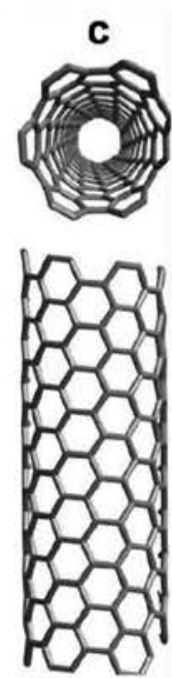

chiral number from 2 to about 50 , later called multi-walled carbon nanotubes (MWNTs). The tips of the tubes are usually closed by curved, polygonal, or cone-shaped caps. MWNTs have many shapes and sizes. Typical diameters are between 10 and $50 \mathrm{~nm}$ with lengths of several micrometers. In 1993, we were one of the first to fill the inner cores of MWNTs with yttrium carbide [6]. That year, Iijima and Ichihashi [7] and Bethune et al. [8] almost simultaneously reported the arc-discharge and catalyst-assisted synthesis of singlewalled nanotubes (SWNTs). The use of argon, iron, and methane, was critical for the synthesis of SWNTs. TEM revealed that SWNTs were curved and tangled together to form bundles. The nanotubes had diameters of about $1 \mathrm{~nm}$ with a board diameter distribution between 0.7 and $1.65 \mathrm{~nm}$. We found that using a mixture of $\mathrm{Fe} / \mathrm{Co}$ and $\mathrm{Co} / \mathrm{Ni}$ increased the yield of SWNTs [9].

\section{Laser ablation}

This was the technique Kroto et al. used to produce $\mathrm{C}_{60}$ in 1985 [1]. In 1996, Smalley and co-workers used this method to produce high yields $(>70 \%)$ of SWNTs at $1200^{\circ} \mathrm{C}[10]$. Small amounts of Ni and Co were added to the graphite rods. The synthesized nanotubes formed bundles (ropes) with uniform diameters of $5-20 \mathrm{~nm}$ and lengths from tens to hundreds of micrometers. The ropes were found to be metallic and it was argued that a particular $(10,10)$ type might be the dominant component.

Both arc-discharge and laser ablation techniques have the advantage of high yields of SWNTs and the drawback that (1) they must operate at high temperatures $>3000^{\circ} \mathrm{C}$ to evaporate carbon atoms from solid targets, and (2) the nanotubes are bundled, which makes it difficult to separate for usage.

Catalytic growth

The process is also known as hydrocarbon pyrolysis or chemical vapor decomposition (CVD). In this process, fullerenes and CNTs are produced by hydrocarbon (e.g. methane, benzene, acetylene, naphthalene, ethylene, etc.) decomposition over metal catalysts (e.g. $\mathrm{Co}, \mathrm{Ni}, \mathrm{Fe}, \mathrm{Pt}$, and $\mathrm{Pd}$ deposited on substrates such as silicon, graphite, or silica) in a tube reactor at $550-750^{\circ} \mathrm{C}$ It was suggested that the nanotubes grow out of pores in the catalyst nanoparticles by tip growth or base growth depending on the contact forces between the catalyst particles and the substrate. High-quality SWNTs could be grown on silicon wafers by the CVD technique [11] using methane, $\mathrm{Fe} / \mathrm{Mo}$ catalyst, and high reaction temperatures of $850-1000^{\circ} \mathrm{C}$. 


\section{thinkforward}

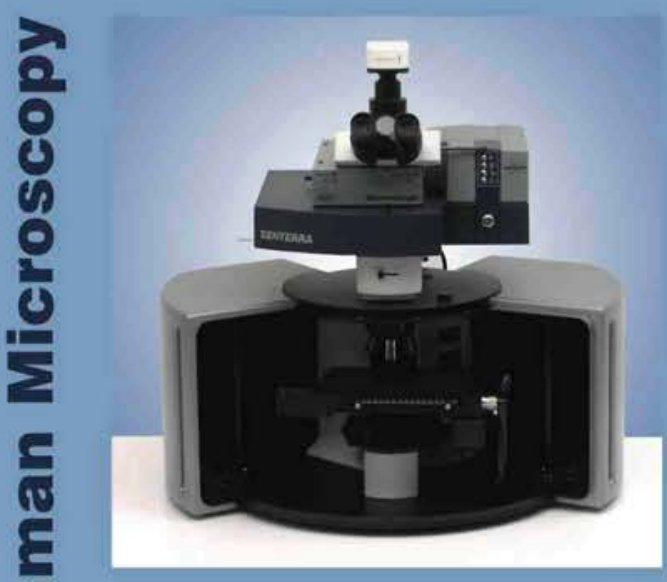

$\square$ All-in-one, compact, confocal design

$\square$ Multiple wavelegths; $1064 \mathrm{~nm}$, $785 \mathrm{~nm}, 532 \mathrm{~nm}$ and/or $633 \mathrm{~nm}$.

$\square$ Sure_Cal ${ }^{\circ}$ automatic continuous calibration

$\square$ Spectral imaging utilizing sample stage mapping

$\square$ Confocal depth profiling with FlexFocus ${ }^{\mathrm{TM}}$

$\square$ Automatic fluorescence rejection using SERDS for $785 \mathrm{~nm}$

\section{Isn't it time to make peace between two technologies?}

Introducing the SENTERRA ${ }^{\text {M }}$ Dispersive Raman Microscope with the new integrated 1064nm FT-Raman technology

Bruker Optics introduces the first Raman microscope system to combine the long wavelength benefits of $1064 \mathrm{~nm}$ excitation with the scattering benefits of shorter wavelength Raman excitation. The new 'hybrid' platform accommodates the RamanScope fluorescence-free Fourier transform Raman system and the SENTERRA grating based dispersive Raman technology with fluorescence rejection tools. This combination provides full spectroscopic characterization and optimizes the strengths of the both techniques for your complex micro-analysis samples.
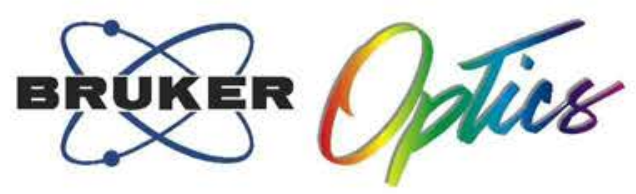

for more information please visit: www.brukeroptics.com/microscopy 1-888-4BRUKER | microscopy@brukeroptics.com 
At this condition, base growth a)

is favored due to the increased metal-support interactions.

\section{Solar production}

When solar energy is focused (flux $500-1000 \mathrm{~W} / \mathrm{cm}^{2}$ and the temperature reaches 2800 - $3000^{\circ} \mathrm{C}$ ) on a carbon-metal target in an inert atmosphere, SWNTs and MWNTs can be produced [12-14]. It is also possible to use solar energy in a pyrolytic processes to produce MWNTs, particularly, the catalytic decomposition of $\mathrm{CH}_{4}$ and $\mathrm{C}_{4} \mathrm{H}_{10}$ in the presence of $\mathrm{Ni} / \mathrm{Al}_{2} \mathrm{O}_{3}$ or $\mathrm{Co} / \mathrm{MgO}$ [15]. This method is potentially advantageous but further research needs to be carried out to improve the quality of the products.

\section{The Structure and Electronic Properties of Carbon Nano- tubes}

Each single-walled nanotube is a roll-up of a hexagonal graphene sheet, which can be "nonchiral" or "chiral" arrangements [16]. In the non-chiral geometries, the honeycomb lattice, located at the top and bottom of the tube, is always parallel to the tube axis. These configurations are known as armchair and zig-zag structures (Fig. $1 \mathrm{a}, \mathrm{b}$ ). In the armchair structure, two C-C bonds on opposite sides of each hexagon are perpendicular to the tube axis, whereas in the zig-zag arrangement, these bonds are parallel to the tube axis. All other configurations in which the $\mathrm{C}-\mathrm{C}$ bonds lie at an angle to the tube axis are known as chiral or helical structures (Fig. 1c). Theoretical studies on the electronic properties of carbon tubes indicate that all armchair tubes are metallic, as well as zig-zag arrangements exhibiting values of $\mathrm{m}$, $\mathrm{n}$ multiples of three [17]. It is amazing that SWNTs can be either metallic or semiconducting depending on the choice of $(m, n)$ (Fig. 2 and Fig. 3), although there is no difference in the chemical bonding between the carbon atoms within the tubes and no doping or impurities are present. The unique electronic properties of CNTs are caused by the quantum confinement of electrons normal to the nanotube axis. In the radial direction, electrons are confined by the monolayer thickness of the graphene sheet. Consequently, electrons can propagate only along the nanotube axis. Recently, Quyang et al. reported that an isolated armchair SWNT, exhibiting a metallic behavior, will become semiconducting when bundled together [18]. Fig. 4(a) illustrates the relationship of pseudogaps as a function of the tube radii and (b) models of isolated tube versus a bundle of three tubes and their corresponding energy diagrams.

Structural features in multi-walled tubes are more complex than those in SWNTs. Fig. 5(a) shows a TEM image of a multiwalled tube with caps. Curvatures at the caps result from inserting six pentagons into the hexagonal structure. Fig. 5(b) illustrates the dependence of the apex angle on the number and location of the pentagons introduced in the hexagonal carbon network: angles of $19.2^{\circ}$ and $38.9^{\circ}$ are created by adding four and five pentagons in the flat graphene structure. The nanotube cap showing in Fig. 6(a) con-
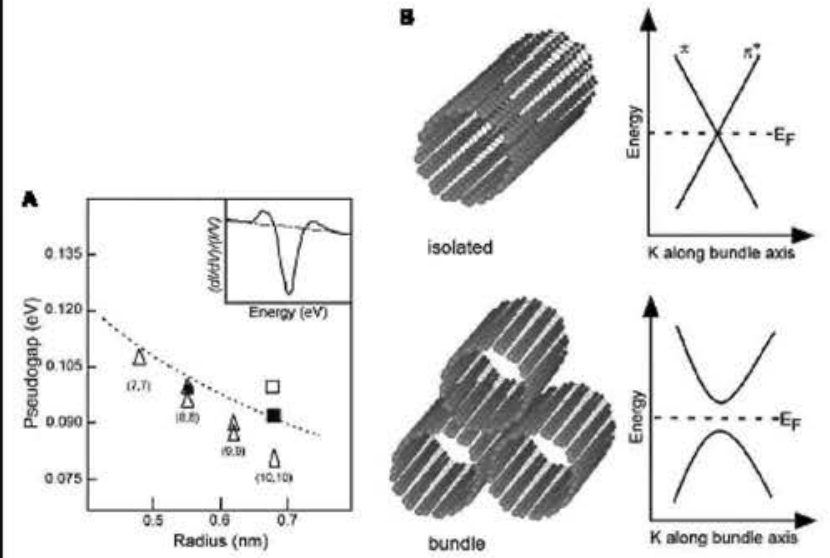

tains negative curvature due to the presence of a pentagon-heptagon pair (arrows) [19]. Figures 6 (b) and (c) are a molecular model of a nanotube containing a pentagon-heptagon pair, which resembles the image shown in fig 6(a). Fig. 7 illustrates three examples of L-, T-, and Y-shaped tubes. All curvatures contain pentagon-heptagon pairs in order to bend the flat hexagonal sheets.

Table 1 Properties of single-walled carbon nanotubes [20]

\begin{tabular}{|l|l|l|}
\hline \multicolumn{1}{|c|}{ Property } & \multicolumn{1}{|c|}{ Single-walled Nanotubes } & \multicolumn{1}{|c|}{ By comparison } \\
\hline Size & $\begin{array}{l}0.6 \text { to } 1.8 \text { nanometer in } \\
\text { diameter }\end{array}$ & $\begin{array}{l}\text { Electron beam } \\
\text { lithography can create } \\
\text { lines } 50 \text { nm wide, a few } \\
\text { nm thick }\end{array}$ \\
\hline Density & 1.33 to $1.40 \mathrm{~g} / \mathrm{cm}^{3}$ & $\begin{array}{l}\text { Aluminum has a } \\
\text { density of } 2.7 \mathrm{~g} / \mathrm{cm}^{3}\end{array}$ \\
\hline Tensile Strength & 45 billion Pa & $\begin{array}{l}\text { High-strength steel } \\
\text { alloys break at about } 2 \\
\text { billion Pa }\end{array}$ \\
\hline Resilience & $\begin{array}{l}\text { Can be bent at large angles } \\
\text { and re-straightened without } \\
\text { damage }\end{array}$ & $\begin{array}{l}\text { Metals and carbon } \\
\text { fibers fracture at grain } \\
\text { boundaries }\end{array}$ \\
\hline $\begin{array}{l}\text { Current Carrying } \\
\text { Capacity }\end{array}$ & Estimated at 1 billion $\mathrm{A} / \mathrm{cm}^{2}$ & $\begin{array}{l}\text { Copper wires burn } \\
\text { out at about } 1 \text { million } \\
\text { A/cm }{ }^{2}\end{array}$ \\
\hline Field Emission & $\begin{array}{l}\text { Can activate phosphors at } 1 \text { to } \\
1 \text { volts if electrodes are spaced }\end{array}$ & $\begin{array}{l}\text { Molybdenum tips } \\
\text { require fields of } 50 \text { to } \\
100 \mathrm{~V} / \mu \mathrm{m} \text { and have } \\
\text { very limited lifetimes }\end{array}$ \\
\hline $\begin{array}{l}\text { Heat } \\
\text { Transmission }\end{array}$ & $\begin{array}{l}\text { Predicted to be as high as } \\
6,000 \mathrm{w} / \mathrm{m} . \mathrm{K} \text { at room T }\end{array}$ & $\begin{array}{l}\text { Nearly pure diamond } \\
\text { transmits } 3,320 \mathrm{w} / \mathrm{m} . \mathrm{K}\end{array}$ \\
\hline $\begin{array}{l}\text { Temperature } \\
\text { Stability }\end{array}$ & $\begin{array}{l}\text { Stable up to } 2,800^{\circ} \mathrm{C} \text { in } \\
\text { vacuum, } 750^{\circ} \mathrm{C} \text { in air }\end{array}$ & $\begin{array}{l}\text { Metal wires in } \\
\text { microchips melt at } 600 \\
\text { to } 1,000^{\circ} \mathrm{C}\end{array}$ \\
\hline Cost & $\$ 300$ to $\$ 1,000 / \mathrm{g}$ currently & $\begin{array}{l}\text { Gold is selling for } \\
\text { about } \$ 18 / \mathrm{g} \text { in } 2 / 2006\end{array}$ \\
\hline
\end{tabular}


Expertise and joie de vivre...

$3^{\text {rd }}$ Annual Microscopy Workshop 8 - 12 May, 2006

McGill University, Montréal, Canada

\section{ADVANCED TECHNIQUES in MICROSCOPY for MATERIALS CHARACTERIZATION}

\begin{tabular}{|ll|}
\hline Choose your sessions "à la carte": \\
SEM I & SEM II \\
X-ray Analysis I & X-ray Analysis II \\
Sample Preparation & Advanced Probe \\
Image Analysis I & Image Analysis II \\
EBSD & \\
\hline
\end{tabular}

These topics will be covered :

High Resolution FESEM

Variable Pressure SEM

Spectrum Imaging

Focused Ion Beam

Dual Beam Systems

Thin Film Measurements

Monte Carlo Simulations
EBSD

Quantitative EDS

Stereology

Ion Beam Etching

3-D Atom Probe

Nano-SIMS

\section{AND MANY MORE!!!}

\begin{tabular}{|ll|}
\hline \multicolumn{2}{|l}{ The lecturers are renowned in } \\
their fields : & \\
David Joy & Brendan Griffin \\
Eric Lifshin & Raynald Gauvin \\
George Vander Voort & Pierre Hovington \\
Rocco Cerchiara & Marin Lagacé \\
Scott Sitzman & Tom Kelly \\
\hline
\end{tabular}

\section{McGill}

Department of Mining, Metals and Materials Engineering
Hydro

Québec

Institut de recherche

Regroupement Aluminium Résecus de recherche sur raluminium
Information : Prof. Raynald Gauvin (514) 398-8951

raynald.gauvin(a megill.ca

www.ebeamworkshop.com

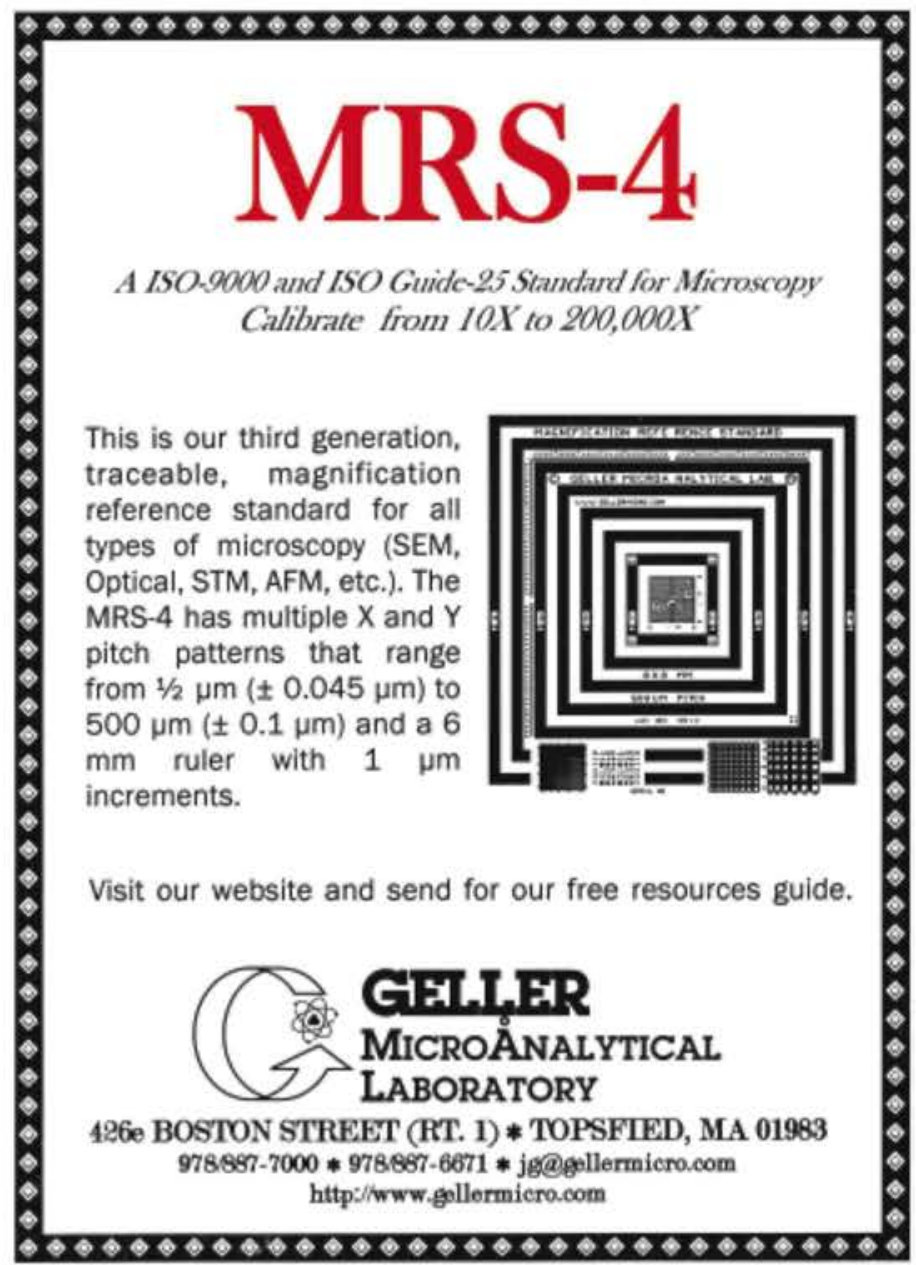

\section{SERPETRRNIX}

PHONE/FAX (239)945-6763

Introducing the MaxView Plus Digital Camera Attachment System

The MaxView Plus kit includes adapters to fit microscopes \& optical devices with any of the following attachments; C-Mount, C/S-Mount, T-Mount, 23mm Eyepiece Port, $30 \mathrm{~mm}$ Eyepiece Port, and 1.25" Eyepiece Ports

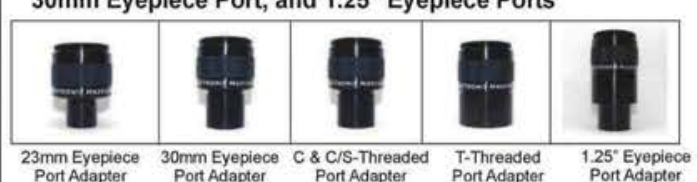
Port Adapter Port Adapter Port Adapter Port Adapter Port Adapter The MaxView Plus can also be used as a high quality wide angle eyepiece with the included thread-on eyeguard. The MaxView Plus is " $T$ " threaded on top so you will need the appropriate Attachment Kit to mate it to your particular digital camera. We carry dozens of attachment kits to fit most all popular digital cameras and we update them regularly so your MaxView Plus will not become obsolete when it is time to upgrade to a new camera. If using it with a $35 \mathrm{~mm}$ SLR you will need the appropriate T-Ring for your brand of camera

The heart of the MaxView system. A wide field $40 \mathrm{~mm}$

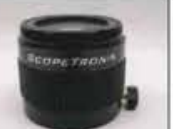
The heart of the MaxView system. A wide field $40 \mathrm{~mm}$ focal length four element symmetrical (Plossi) lens custom cell. The lens is mounted only $1 \mathrm{~mm}$ from the custom cell. The lens is mounted only $1 \mathrm{~mm}$ from the top to maintain the close coupling required to reduce vignetting. The cell features a unique sliding collar
assembly which serves several important functions, it allows quick and easy removal of the camera, it allows you to adjust it allows quick and easy removal of the camera, it allows you to adjust
eyeguard height for easy visual use, allows you to adjust magnification when used with a $35 \mathrm{~mm}$ camera, and allows you to adjust lens position to minimize vignetting with a digital camera.

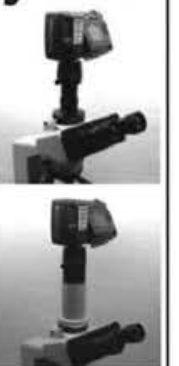

to minimize vignetting with a digital camera. only $\$ 299.00$

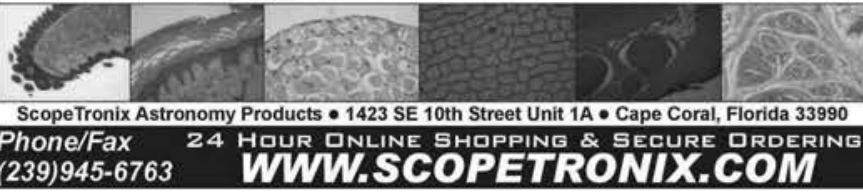



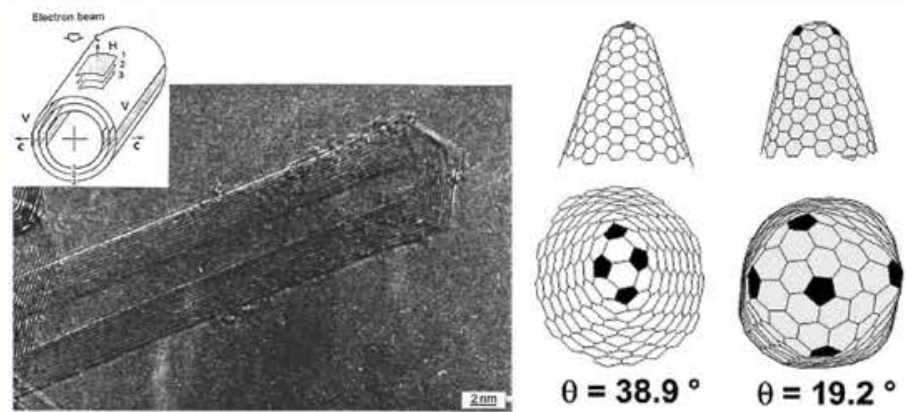

Fig. 5. (a) TEM image of a multi-walled tube with caps. The spacing between layers of graphene sheets is $0.34 \mathrm{~nm}$. (b) Molecular models showing an apex angle depending on the number of pentagons introduced. in the hexagonal carbon network: angles of $19.2^{\circ}$ and $38.9^{\circ}$ are created by adding four and five pentagons in the graphene structure.

Structural and physical properties of single-walled carbon nanotubes are summarized in Table 1 [20]. The last column of the Table is provided for comparison.

\section{Mechanical Prop- erties}

Carbon nanotubes have high stiffness and axial strength as a result of carbon-carbon $\mathrm{sp}^{2}$ bonding. Practical application of nanotubes requires more study of the their elastic response, their inelastic behavior and buckling, yield strength and fracture mechanisms. Fig. 8 shows the remarkable resilience of a MWNT-it can be bent in a large angle without
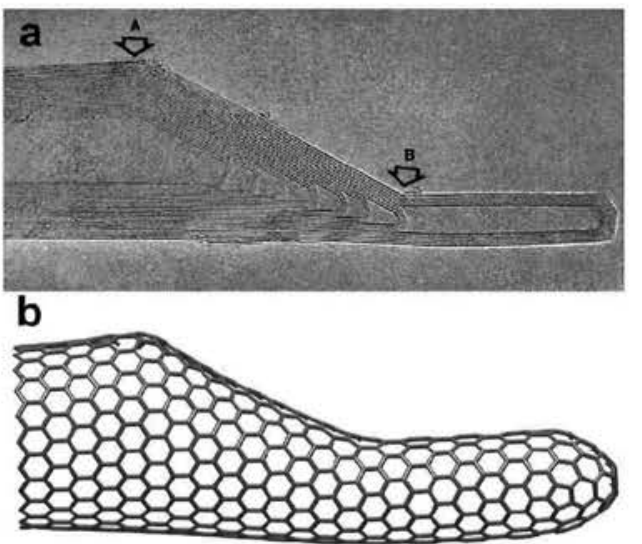

C

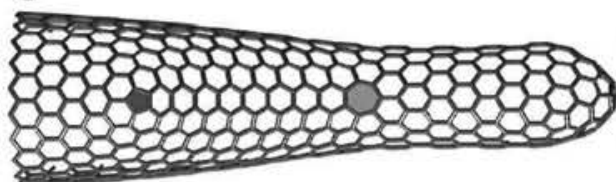

Fig. 6. (a) Nanotube cap showing negative curvature due to the presence of a pentagonheptagon pair (arrows); (b) and (c) molecular models of a nanotube containing a pentagonheptagon pair resembling the image shown in (a). [4].

breaking. The average value for Young's modulus for MWNTs is 1.8 T Pa [21], much higher than the value for typical carbon fibers of $680 \mathrm{GPa}$. Other mechanical strength measurements on SWNTs and MWNTs (produced using pyrolytic routes) have revealed lower values of Young's modulus [4]. The values are dependent on the crystallinity of the materials and the number of defects present within the structure. The mechanical axial tension applied to bundles of SWNTs shows fascinating results because each nanotube is very thin, and coupling between tubes is weak. In the case where a tubule breaks, there is almost no effect on the rest of the tubes. Therefore, the chain reaction of fracture is hindered and cracks are blocked [22].

\section{Examples of Applications}

Field Emission Sources

When a potential is applied between a CNT surface and an anode, electrons are easily emitted from the CNT tip (electron tunneling from the tips into the vacuum). Using this principle, CNTs can be used as efficient field emission sources for the fabrication of multiple electronic devices such as flat panel displays, intense light sources or bright lamps, and X-ray sources. Generally, nanotube-emission surfaces are fabricated by creating various types of nanotube composite polymers that are vacuum stable. The clear advantages of using CNTs as electron emission devices are $(a)$ stable field emission over prolonged time periods, $(b)$ long lifetimes of the components, $(c)$ low emission threshold potentials, $(d)$ high current densities, and (e) the absence of the need for ultrahigh vacuum. Very large current densities, as high as $4 \mathrm{~A} / \mathrm{cm}^{2}$, have been reported (23). Samsung (Korea) has produced low-cost prototypes of nanotube color (9-inch) displays that can play moving images [24] (see Fig. 9 a). Recently, it was reported that B-doped MWNTs can exhibit enhanced field emission compared to that of intrinsic MWNTs (Fig. $9 \mathrm{~b}-\mathrm{c}$ ). This phenomenon is due to the presence of B atoms at the nanotube tips, which results in an increased density of states (DOS) close to the Fermi level. Thus, B-doped tubes may have great potential as building blocks for stable and intense field emission sources. This will open new avenues for vacuum microelectronics.

It has also been demonstrated experimentally that nanotube based-lamps are relatively cheap to manufacture and have exhibited lifetimes of $8000 \mathrm{~h}$ and high efficiency, superior to that for the green (phosphorous) light bulbs [23]. Wei et al. used strands of singlewalled and multiwalled nanotubes replacing tungsten [25] in a lamp configuration. Carbon nanotube filaments light up at lower voltages and are more efficient than their tungsten counterparts. The generation of X-rays can also be achieved if metal targets replace the phosphorous screen and the accelerating voltage is larger [26]. It is possible that many field emission applications may be replaced by CNTs in the future.
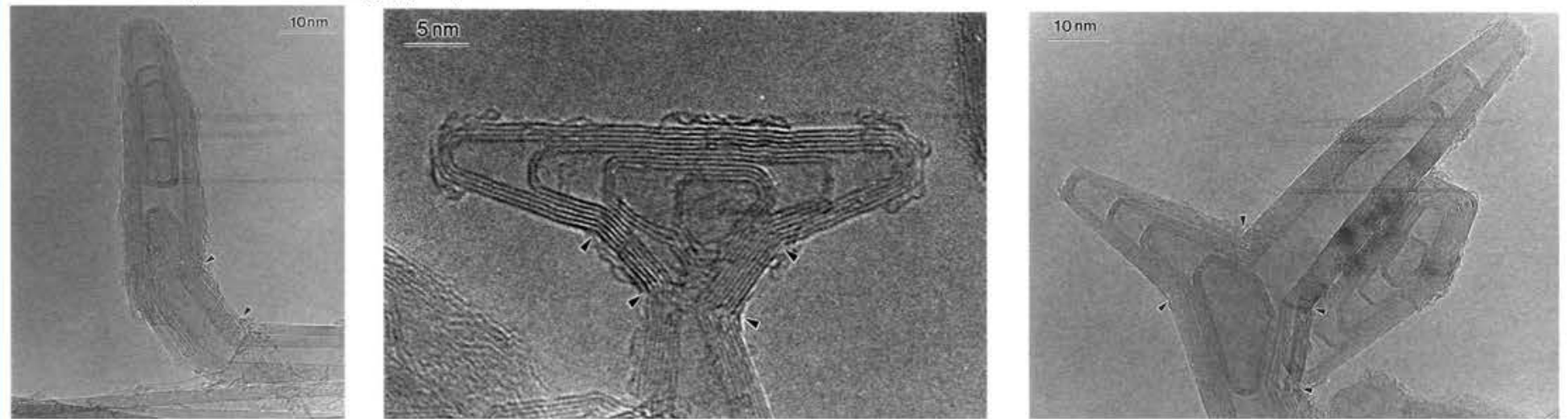

Fig. 7. TEM images of (a) an L-shaped tube; (b) a T-shaped tube; and (c) a Y-shaped tube. Location and numbers of pentagon-heptagon pairs determine the curvatures, therefore the overall shape of the tube. 


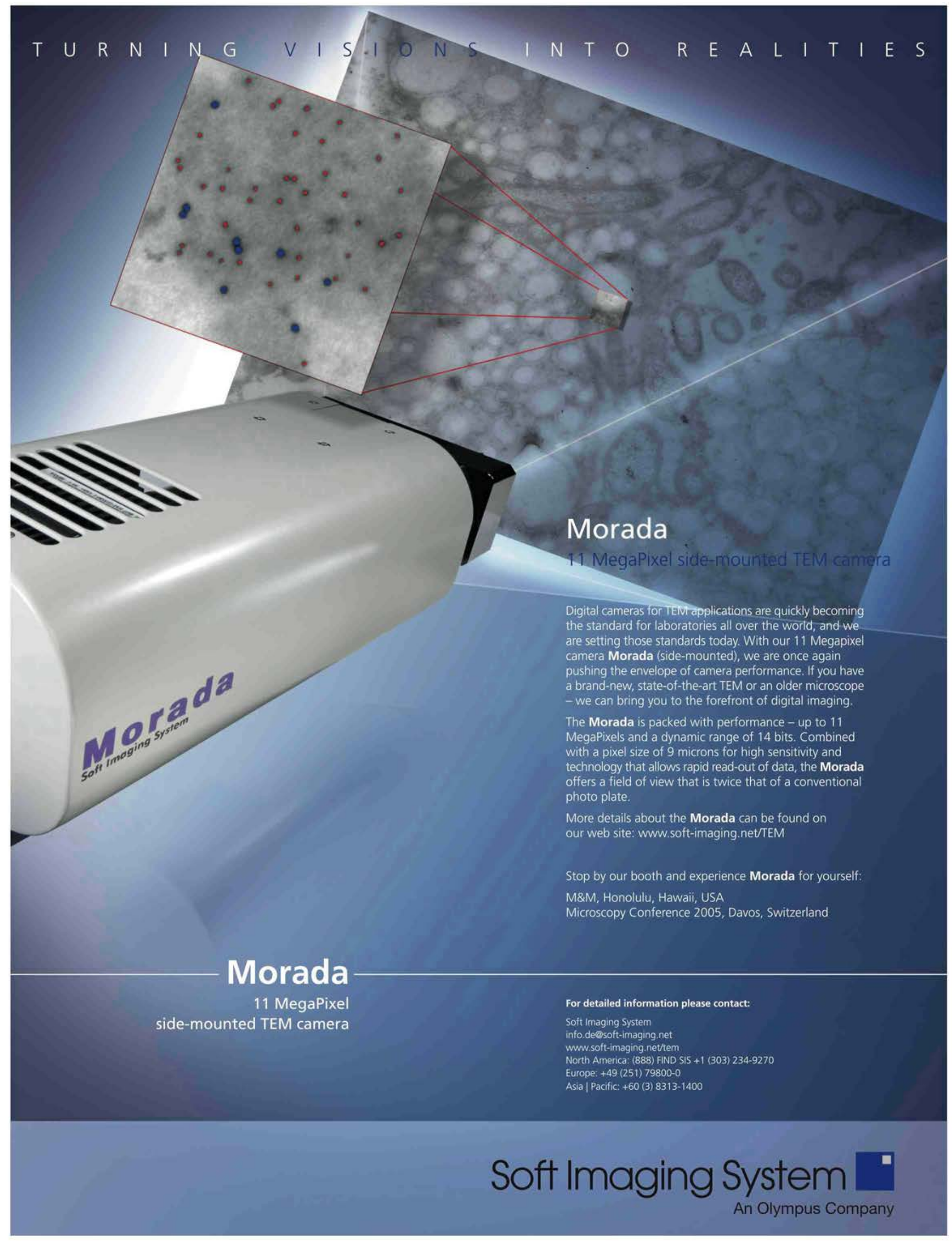




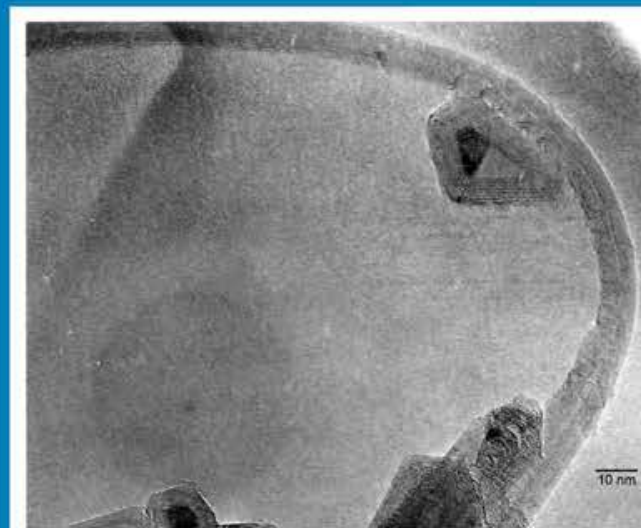

Fig. 8. TEM image of a MWNT buckling without damage.
Scanning Probe

Tips

From the field emitting behavior described above, it has been shown that MWNTs attached to the tips of an atomic force microscope (AFM) (Fig. 10) can improve the image lateral resolution of the instrument by a factor of 10 or more, allowing clearer views of proteins and other large molecules [27]. The mechanical strength of MWNTs and the ability to bend and recoil are additional properties that make MWNTs a competitive choice for long-life microscope tips. The following are two current obstacles. Although commercially available, each tip is still made individually and the nanotube tips do not improve vertical resolution. However, they do allow imaging of deep pits in nanostructures that were hidden previously.

Nanotube Electronic Devices

This is one of the most exciting applications of carbon nanotubes. Sanders et al. fabricated a three-terminal switchable device based upon a single nanotube molecule [28]. The transistor, which operates at room temperature (Fig. 11), consists of a semiconducting single-walled nanotube connected to metal nanoelectrodes. The switching speed is excellent due to its low capacitance. Manipulating and controlling the chirality of the nanotubes and thus the electronic properties of the device are challenging. Collins et al. [29] demonstrated a method using electrical breakdown to peel

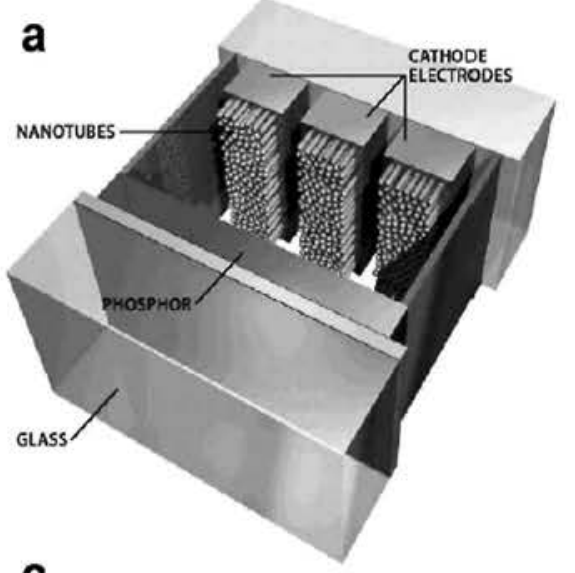

b

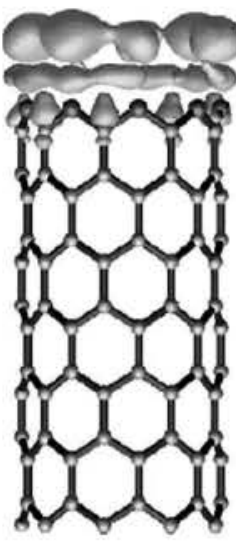

C

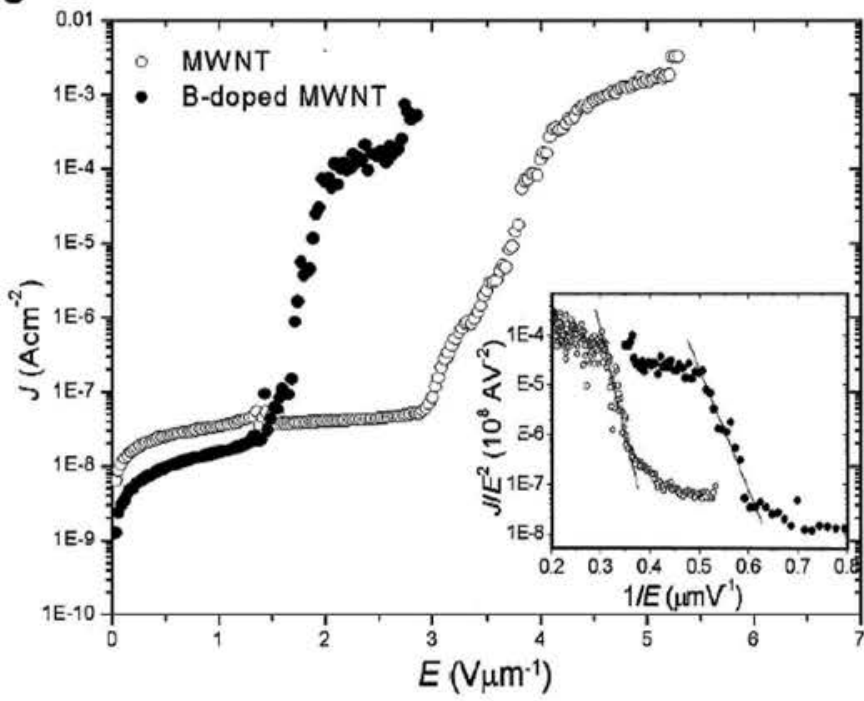

Fig. 9. (a) Sketch of a TV display using CNTs; (b) Side view of the localized states seen at the edges of a boron-saturated zig-zag $(9,0)$ CNT. The work function of this tube is $1.7 \mathrm{eV}$ lower than that of the same nanotube
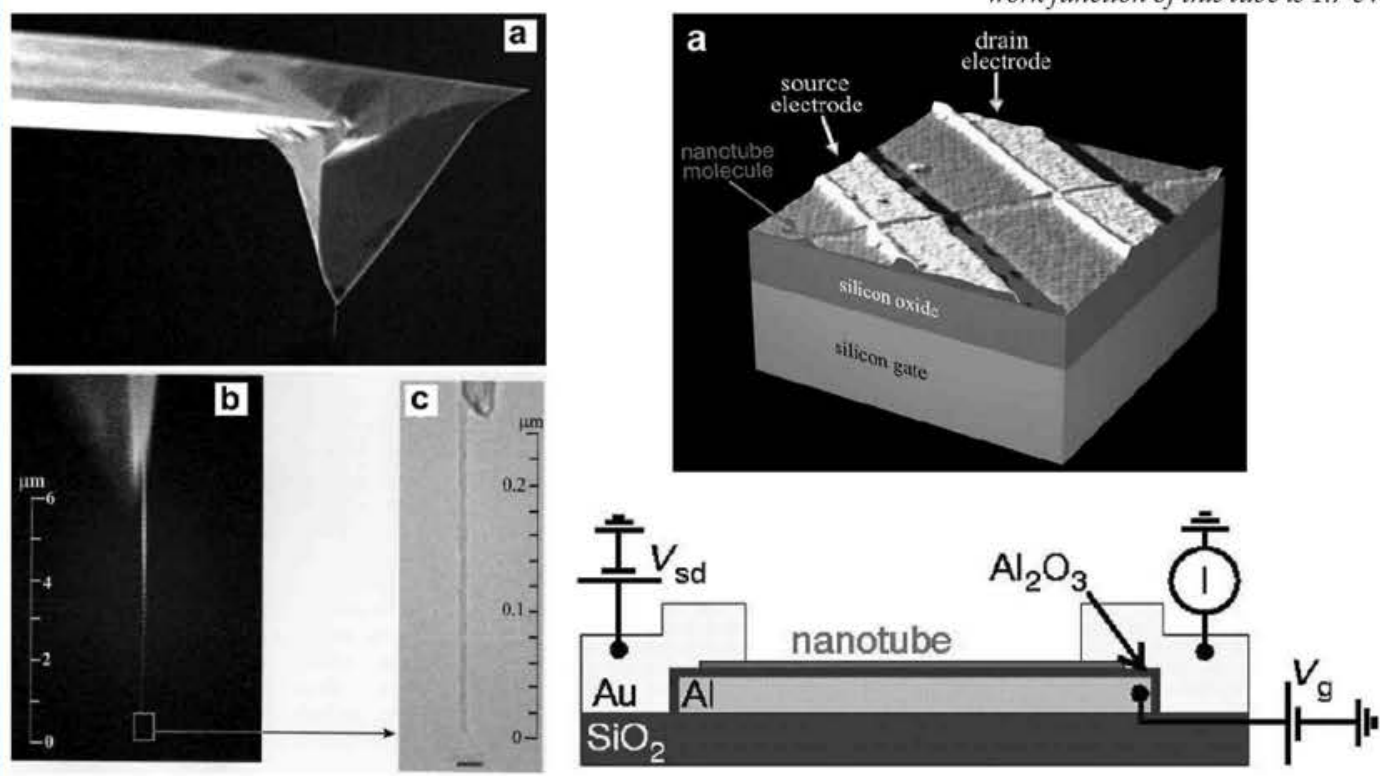

Fig. 10. (a,b) SEM images of a standard AFM tip with MWNTs at the end; (c) TEM image of the AFM tip showing the MWNT structure attached to the end of the scanning probe microscopy tip. [27]

Fig. 11. (a) Three-dimensional AFM image of the SWNT deposited on two electrodes (source and drain electrodes). This system behaves as a room temperature transistor.; (b) Schematic of single-nanotube transistor. A semiconducting SWNT is contacted by two Au electrodes. An Al wire, covered by a few nanometers-thick oxide layer, is used as a gate. [28] made exclusively of carbon atoms; (c) $J$-E emission characteristics measured in parallel plate configuration of the B-doped nanotube films and comparable films of pure carbon arcproduced MWNTs. It is clear that the emission for the doped tubes is excited at lower voltages. Inset shows the Fowler-Nordheim plots for each curve. [24]

outer layers of MWNTs until the desired electronic property of the outer shell is obtained. The same method can be used to reduce the SWNTs bundles size to meet preferred electronic characteristics. However, controlled growth in order to achieve selective chiralities needs to be investigated and exploited.

\section{Conclusions}

In this review, the structure, properties and applications of carbon nanotubes are presented. CNTs have unique properties and great potential for novel 
technologies in the near future. It is now a widely-shared view that carbon-based materials are likely to be a major field in the twenty first century technology.

\section{Acknowledgements}

The author would like to acknowledge a funding from the Thailand National Science and Technology Development Agency to partially support her sabbatical at Chiang Mai University, Thailand. She also thanks all collaborators and graduate students for their hard work and stimulating discussions.

\section{References:}

1. H.W. Kroto, J.R. Heath, S.C. O'Brien, R.F. Smalley, Nature 318, 162 (1985)

2. W. Krätschmer, L.D. Lamb, K. Foristopoulos, and D.R. Huffman, Nature 347,354 (1990)

3. S. Iijima, Nature 354,56 (1991)

4. M. Terrones, Annu. Rev. Mater. Res. 33, 419 (2003)

5. V. N. Popov, Mater. Sc. Eng. R 43, 61 (2004)

6. S. Seraphin, D. Zhou, J. Jiao, J. C. Withers \& R. Loutfy, Nature 362, 503 (1993)

7. S. Iijima and T. Ichihashi, Nature 363, 603 (1993)

8. D.S. Bethune, C.H. Kiang, M.S. de Vries, G. Gorman, R. Savoy, J. Vazquez, R. Beyers, Nature 363, 605 (1993)

9. S. Seraphin and D. Zhou, Appl. Phys. Lett., 64, 2087 (1994)

10. A. Thess, R. Lee, P. Nikolaev, H. Dai, P. Petit, J. Robert, C. Xu, Y.H. Lee, S.G. Kim, A.G. Rinzler, D.T. Colbert, G.E. Scuseria, D. Tomanek, J.E. Fischer, R.E. Smalley, Science 273, 483 (1996)

11. J. Kong, H.T. Soh, A.M. Cassell, C.F. Quate, H. Dai, Nature 395, 878 (1998)

12. D. Laplaze, P. Bernier, W.K. Maser, G. Flamant, T. Guillard, A. Loiseau, Carbon 36, 685 (1998)

13. T. Guillard, G. Flamant, J.F. Robert, B. Rivoire, G. Olalde, J. Phys. IV 9, 59 (1999)

14. L. Alvarez, T. Guillard, J.L. Sauvajol, G. Flamant, D. Laplaze, Appl. Phys. A $70,169(2000)$

15. A. Meier, V.A. Kirillov, G.G. Kuvshinov, Y.I. Mogilnykh, A. Weidenkaff, A. Steinfeld, J. Phys. IV 9, 393 (1999)

16. R. Saito, M. Fujita, G. Dresselhaus, M.S. Dresselhaus, Phys, Rev. B 46, 1804 (1992)

17. J.C. Chalier, J.P. Issi, Appl. Phys. A, 67, 79(1998)

18. Quyang et al., Science, 292, 702 (2001)

19. S. Iijima, T. Ichihashi, Y. Ando, Nature 356, 776 (1992)

20. G. Collins G. \& P. Avouris, Sci American 62-69, December 2000

21. M.M.J. Treacy, T.W. Ebbesen, and J.M. Gibson, Nature 381, 678 (1996)

22. R.E. Smalley and B.I. Yakobson, Solid State Commun. 107, 597 (1998)

23. R.H. Baughman, A.A. Zakhidov, W.A. De Heer, Science 297, 787 (2002)

24. M. Endo, C. Kim , K. Nishimura, T. Fujino, K. Miyashita Carbon 38,183 (2002)

25. Wei et al. Appl. Phys. Let. 84, 4869 (2004)

26. G.Z. Yue, Q. Qiu, B. Gao, Y. Cheng, J. Zhang, Appl. Phys. Lett. 81, 355 (2002)

27. H.J. Dai, J.H. Hafner, A.G. Rinzler, D.T. Colbert, R.E. Smalley, Nature 384, 147 (1996)

28. S.J. Sanders, R.M. Verschueren, C. Dekker, Nature 393, 49 (1998)

29. P.C. Collins, M.S. Arnold, P. Avouris, Science 292, 706 (2001)

\section{Additional Acknowledgment}

In Dr. Thomas Burrage's article, Microscopy and Microbes at Plum Island: Protecting America's Livestock, November 2005, confocal images were by Vivian O'Donnell, PhD, Plum Island Animal Disease Center, USDA, Agricultural Research Service.

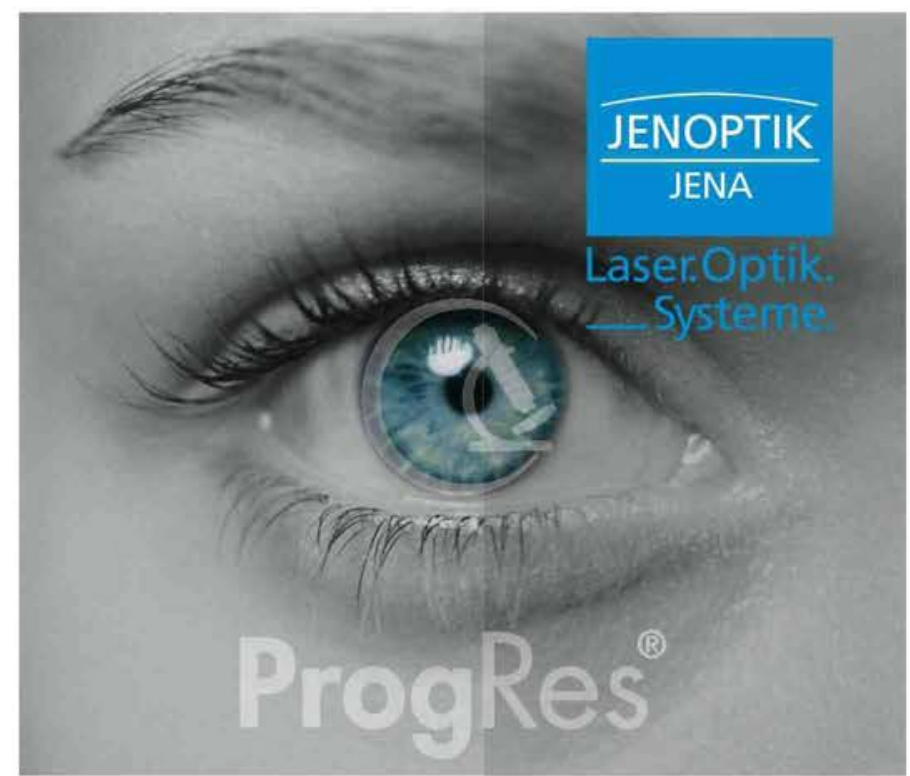

ProgRes $^{\circledR}$ cameras as digital turnkey-solution

Routine cameras for analysis and documentation High-resolution cameras for scientific research cooled monochrome cameras for fluorescence

In combination with easylab image management system from IMAGIC AG

ProgRes ${ }^{\otimes}$ cameras are the basis for a turnkey-solution for processing, documentation and presentation of high-quality digital images increasing the efficiency of your lab.

Further information: www.progres-camera.com
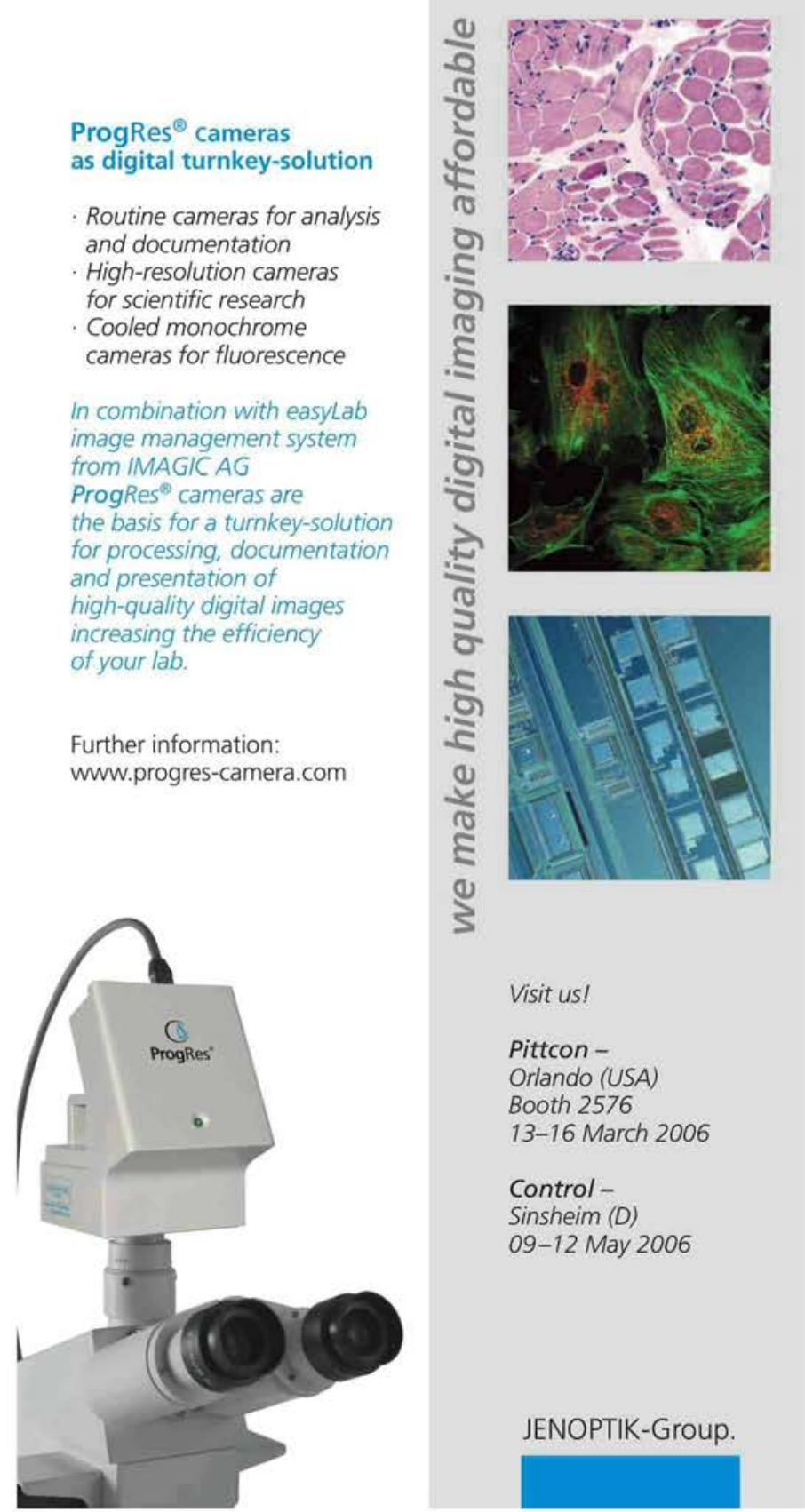